\title{
Dealing with Non-linearity and Uncertainty in Forest Management
}

\author{
Christian Messier $^{1,2} \cdot$ Klaus Puettmann $^{3} \cdot$ Elise Filotas $^{4} \cdot$ Dave Coates $^{5}$
}

Published online: 29 April 2016

(C) Springer International Publishing AG 2016

\begin{abstract}
Forest managers today are struggling with the great uncertainties and rapid changes in many biophysical and socioeconomic aspects of their work. We argue in this review that viewing forests and forest management as complex adaptive systems and acknowledging non-linearity and uncertainty in forest dynamics and management provide an alternative for both production- and conservation-oriented forests to the traditional command and control approaches that have been advocated so far in forestry. We first discuss the concepts of nonlinearity and uncertainty in forest dynamics and management. We then propose a set of broad principles and approaches that are required for forest managers to better incorporate these new concepts into practices. These span from (1) relaxing and expanding the sustained-yield and single-good paradigm, (2) moving the target for assessing success in silviculture from predetermined strict outcomes for each and every stand to an envelope of possible outcomes that are acceptable for one or multiple stands, and (3) using approaches and modeling tools to assess as large a range of possible outcomes as possible
\end{abstract}

This article is part of the Topical Collection on Ecological Function

Christian Messier

ch.messier@gmail.com

1 Institute of Temperate Forest Science (ISFORT), Université du Québec en Outaouais, 58, Rue Principale, Ripon, Québec JOV 1V0, Canada

2 Département des sciences biologiques, Université du Québec à Montréal, Montréal, Québec, Canada

3 Department of Forest Ecosystems and Society, Oregon State University, Corvallis, OR, USA

4 UER Science et technologie, TELUQ, Montréal, Québec, Canada

5 Ministry of Forests, Lands and Natural Resource Operations, Smithers, British Columbia V0J 2N0, Canada instead of the traditional mainly deterministic and static modeling tools.

Keywords Forest management - Silviculture $\cdot$ Non-linearity · Forest managers $\cdot$ Forests

\section{Introduction}

Forest dynamics and management have long been approached with the view that the more we study and control such systems, the better we can ensure a predictable and steady flow of goods and ecosystem services. This view has been described by Holling and Meffe [1] as a pathologic syndrome of "command and control." The limits of such an approach are more and more apparent today as both the social and ecological dimensions and certainties under which forest managers are operating are rapidly changing $[2 \bullet \bullet]$. The only certainty today seems to be that tomorrow will bring new changes and surprises for which we are ill prepared. Such uncertainties have always been there, of course, but they seem to be increasing as technology, market, culture, and climate are changing at unprecedented rates.

Faced with this new reality, an evolving direction for natural-resource management is to view forests and forest management through the lens of complexity science $[3 \bullet, 4]$. A major attraction of complexity science is that it provides the necessary conceptual framework to promote the long-term productivity, biodiversity, and adaptability of forest ecosystems and an integrative, multidisciplinary approach to study the structure and dynamics of forest ecosystems under the increasing uncertainties of today's forest management conditions [5••]. The various components and ecological processes occurring in a forest are no longer viewed as decoupled from the socioeconomic realities of the human construct. 
Complexity science can then help view forest and human ecosystems as an integrated social-ecological system. It calls for a shift from the pursuit of specific tree- and stand-scale objectives toward a more flexible multi-scale perspective that also considers landscape-scale processes and their interactions in relation to the globally changing social-ecological conditions. But more importantly, it acknowledges that due to the inherent non-linearity of many of the social-ecological elements and relationships of forest systems and the rapidly changing environmental, biological, economic, and social conditions of today's world, predictability is getting more and more difficult to achieve and could even be counterproductive in terms of achieving our management objectives.

Complex systems are not well understood using the classical or Cartesian modes of thinking used in reductionist or determinist science. Reductionist science studies a system by investigating its individual components in isolation or at a single scale of resolution. In contrast, complexity science proposes a holistic perspective to the study of systems. It suggests that a system can be better understood or managed by focusing on the interactions among the various components of the system at multiple scales. Moreover, contrary to the basic tenants of determinism, complexity science suggests that the dynamics of a system may be highly unpredictable because they rely on nonlinear processes and interactions [6, 7]. Viewing forests as complex systems implies that all aspects of their states and dynamics may never be precisely known. While qualitative forecasts may be possible, the precise quantitative prediction of attributes such as total biomass, composition, or structure may pose insurmountable challenges. Even the most homogenous, intensively managed monospecific tree plantations or intensively managed uneven-aged forests possess many attributes of complex systems [8]. They all have a natural tendency to adapt and without continued top-down management control, they will likely change and deviate substantially from the originally intended condition, especially after unexpected disturbance events (e.g., [9]).

Through the lens of complex system science, forests can be viewed as integrated social-ecological systems with immense benefits for their management $[2 \cdot \bullet, 3 \bullet$, 10]. Such a paradigm shift in the study of forest dynamics and their management could be one of the greatest since the introduction of early forest management theories in the 1800s by German foresters [10]. Complexity science has a strong conceptual foundation that is based on work in non-linear physics and information theory [6]. It is not a discipline per se, but a unified theoretical framework that can be applied to biological, economic, social, and political problems and challenges. Forests, as with all ecological systems, are different from strictly physical and chemical complex systems because of their ability to adapt to changes over time [11]. A complex system is adaptive when heterogeneous components react differently to outside influences, thus continually modifying the system and allowing it to adapt to altered conditions. Forests have ecological attributes-such as diversity, cross-scale interactions, memory, and environmental variability-essential for their capacity to adapt. Although there is no universally accepted definition of a complex system, most researchers in complexity science would agree that a complex system has an emergent structure and dynamics that are the collective result of many components interacting at a lower hierarchical scale. Consequently, complex systems are difficult to analyze or describe using only one scale or resolution. Complexity science provides a transdisciplinary framework to study complex adaptive systems that are often described as having the following properties or characteristics: (1) heterogeneity, (2) hierarchy, (3) self-organization, (4) openness, (5) adaptation, (6) memory, (7) non-linearity, and (8) uncertainty.

Messier et al. [5*0] contrasted ten recent and novel forest management approaches being advocated in different forest biomes as an improvement over traditional forest management approaches (Fig. 1). They then evaluated each practice in relation to how much it considered each of the eight properties of complex adaptive systems. Some practices like the Italian's systemic silviculture [12] fared pretty well, but most completely or partially failed to acknowledge non-linearity and uncertainty characteristics inherent to any complex adaptive system. This paper aims to review these two important characteristics of complex adaptive systems (nonlinearity and uncertainty) and then present some ideas on how forest managers can modify their practices to better incorporate these properties to improve forest management in response to the unprecedented biophysical and social uncertainties and changes occurring today.

\section{Non-linearity in Forest Dynamics: When 2+2 Does Not Equate 4}

Non-linearity characterizes the dynamics of systems with disproportionate responses to associated inputs [13, 14]. Many non-linear relationships exist in forest ecosystems. Prominent examples are the Michaelis-Menten (i.e., saturation) equation for enzyme kinetics that is often used to describe resource use of plant resource uptake [15], exponential or logistic population growth, and the normal, skewed, or bimodal distributions of species along environmental gradients. Non-linear feedbacks play a key role in the regulation of plant and animal populations in all ecosystems [16, 17]. Examples from forest systems include density-dependence in mammalian 


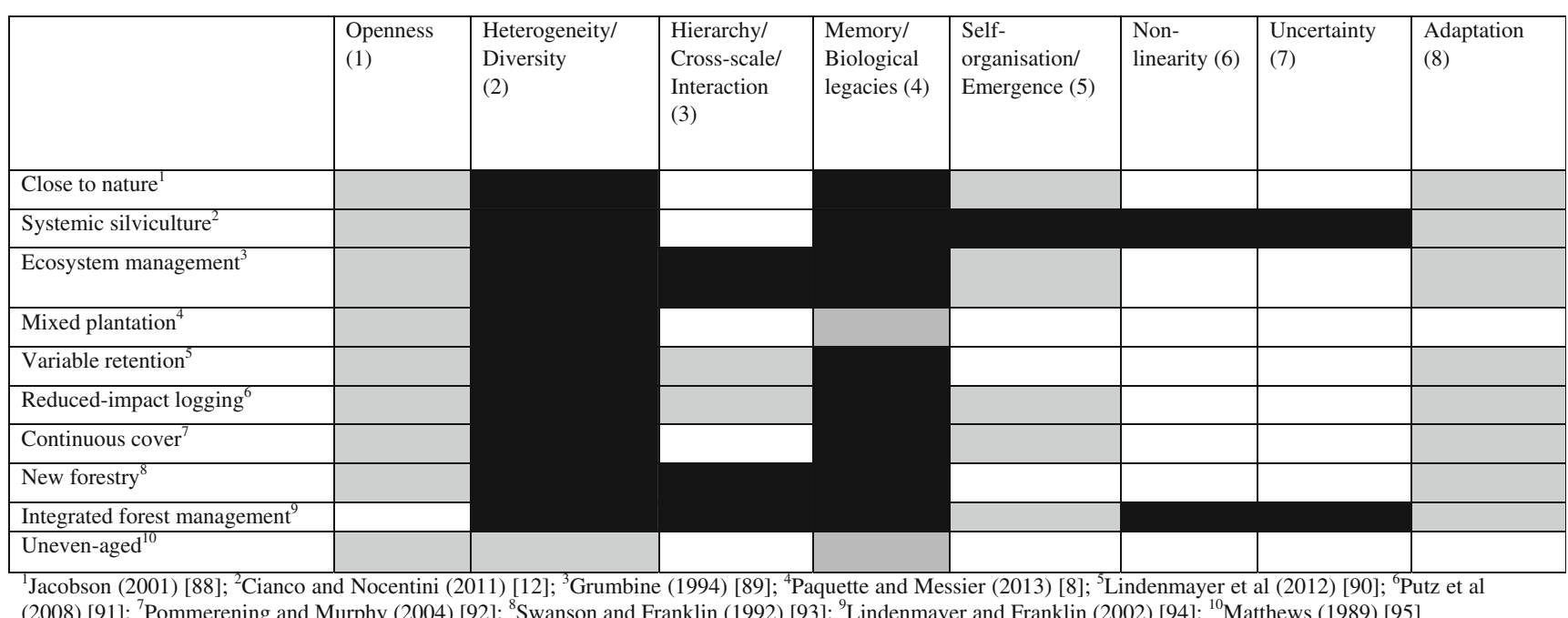

Fig. 1 Evaluation of ten forest management approaches in terms of how they address the eight characteristics of complex adaptive system. Black boxes indicate that the characteristics are emphasized, and white boxes indicate that they are not emphasized. Grey boxes indicate intermediate emphasis

reproductive and mortality rates [18] and density-dependence in plant fecundity and seedling survival [19]. Many non-linear relationships are monotonic, i.e., they only increase or decrease over the range of response of a given variable, albeit at differing rates. Alternatively, non-linear relationships may be non-monotonic, i.e., increasing over parts of the range and decreasing over other parts (Fig. 2). Non-linearity implies that the dynamics of forest systems may show unexpectedly large or small responses to gradually changing conditions. Many ecosystems display threshold dynamics under slow variations in temperature [20], rainfall [21], grazing pressure [22], landscape fragmentation, or connectivity [23]. Examples of such behavior in the ecological literatures include studies that show a hysteresis effect (Fig. 3). For example, the impact of increased herbivory on a forest or grassland system may lead to a slight, maybe even linear decrease over a wide range of grazing intensities, under conditions of sufficient rainfall. In drought years, however, the same levels of herbivory may lead to a major shift in biomass or even vegetation composition (shifting from grassland to open steppe) [22, 24].

Non-linear or threshold patterns are especially hard to predict, when they are driven by cross-scale interactions of
Fig. 2 Conceptual examples highlighting non-linear relationships between parameters as found in forest ecosystems

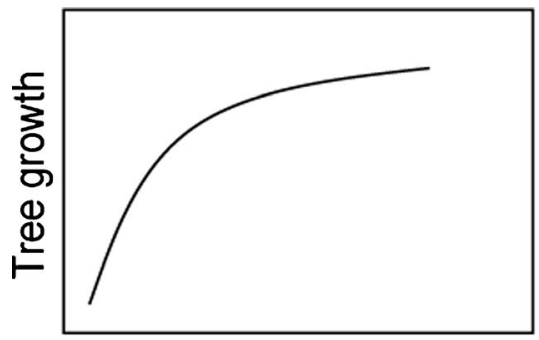

Light

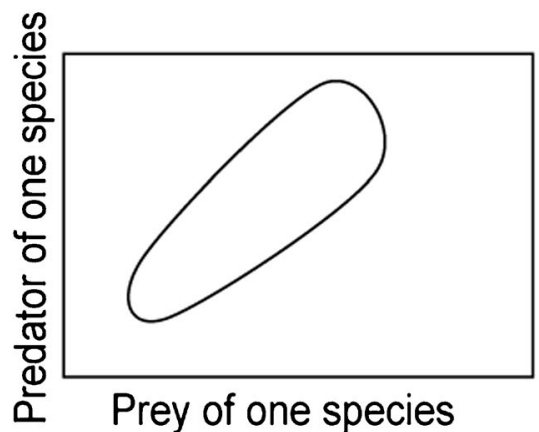

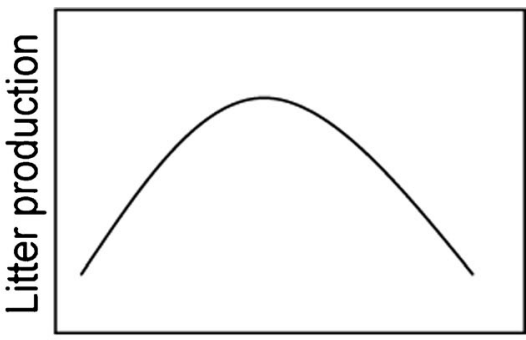

Distance from tree

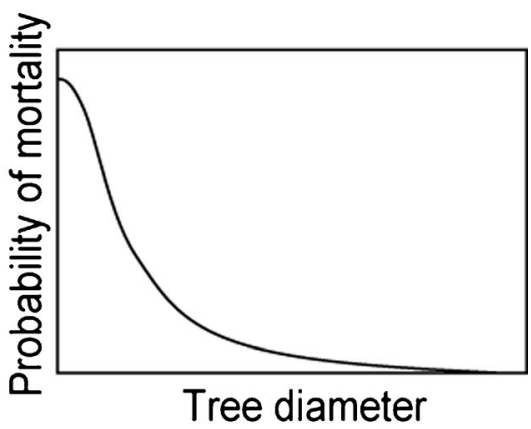




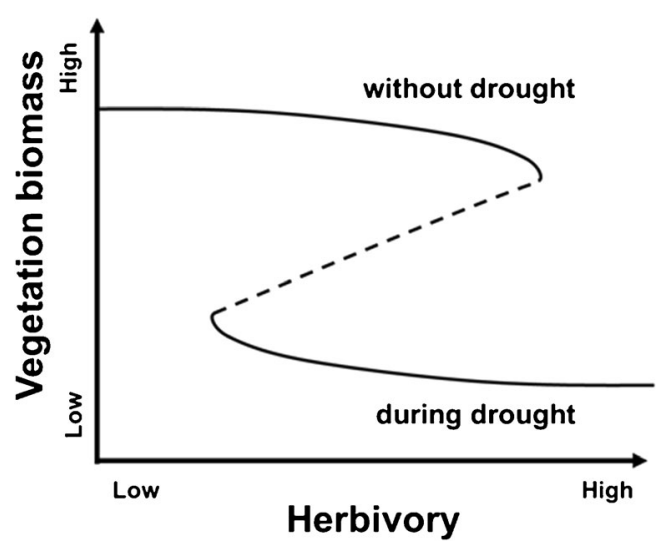

Fig. 3 Example of hysteresis in grassland ecosystems as an example of multiple stable states. During times when water conditions are adequate, grasslands can maintain fairly high biomass. The onset of drought events may lead to non-linear behaviors and push grassland over a threshold. Even reducing herbivory during drought may not allow the system to return to its original state in the near term

multiple factors [25]. For example, the impact of stand treatments on the likelihood and severity of wildfires or insect attacks will change dramatically if the fuel conditions or the insect habitat in the surrounding landscape changes, respectively [26]. The spatial magnitude of the 1980s western spruce budworm (Choristoneura occidentalis) outbreak in interior Douglas-fir forests of British Columbia can be seen as a nonlinear response to local forest management practices, such as harvesting and fire suppression [27].

Non-linearity is of special concern for forest planning as it implies a high sensitivity to initial conditions. In non-linear relationships, small initial differences can be amplified and can lead to divergent trajectories [28]. For example, development of vegetation in forests following a disturbance could follow many different trajectories due to slight differences, such as the proximity of surviving mature trees, seed banks, seed quality and predation level, or weather conditions during germination and early establishment periods [29, 30]. Sensitivity to initial conditions means that forest ecosystems have the capacity to retain memory of past states, in the form of biological legacies. In turn, memory may act as an important agent of resilience, keeping the system in an optimal or non-optimal state relative to management objectives.

Non-linear responses can lead to system's surprisingly quick crossing of thresholds, such as unexpected regime shifts in forest ecosystems where the dominant vegetation type is replaced $[30,31]$. Just as cross-scale interactions, multiple sequential disturbances can precondition a system for non-linear behavior, such as successive disturbances that erode the regeneration potential of the forest. Many social-ecological systems display threshold phenomena. In particular, systems in which legislations or economic policies promote single land-use over large portions of the landscape are more prone to sudden transitions [5••, 32]. Thus, non-linearity is a crucial component for threshold-like dynamics when systems shift between alternative stable states [33].

\section{Uncertainty in Forest Dynamics and Management: the Rule Rather Than the Exception}

The dynamics of any complex system are riddled with uncertainty, which challenges predictions about future states. As stated by Carpenter [13], even the uncertainties are uncertain. Uncertainty arises from many sources. First, it is caused by the stochasticity inherent to most processes driving the dynamics of social-ecological systems. Forest ecosystems are subject to stochastic variation in the physical environment and in the occurrence and outcome of biotic events such as seed survival and predator-prey encounters. Another source of uncertainty is non-linearity in ecosystem processes. As pointed out above, non-linearity hinders prediction because small differences in initial conditions may lead to largely different trajectories, some of which even resemble chaotic behavior [19, 34]. Non-linear dynamics may also lead to unforeseen regime shifts. Examples include the replacement of the Bornean forest by Imperata cylindrica grasslands after repeated fires that were fostered by this very flammable grass [35].

A third source of uncertainty is the openness of forest ecosystems, which can also be viewed as cross-scale interactions with external components. Forests are exposed to changes in peripheral systems to which they are coupled (e.g., economic, political, demographic, climatic) [10]. For example, in Spain, the landscape became more homogenized due to 21 st century social changes in the economy that led to agricultural land abandonment and decreased forest products demands [36]. In Borneo, rates of illegal logging rise with political instability and when corrupt elected or appointed governmental officials come to power [35]. More directly, extremely rare events can be highly influential [37]. Natural and social events, such as changes in hunting regulation and drought, as well as epidemics, wars, or market crashes, are hard to predict, but they can have high short- and long-term impact on forestry and forest development [10].

A final source of uncertainty emerges from the capacity of adaptation of forests. Heterogeneity and biodiversity are key determinants of ecosystem adaptation [11]. For example, external changes do not affect all species identically and a diversity of responses may exist among species accomplishing the same ecological function [38]. Heterogeneity of components and cross-scale interactions provide the sources of innumerable innovations for altered forest systems. Compositional, structural, or behavioral changes at the bottom of the system's hierarchy (e.g., by removing keystone species) can result inthrough self-organizing processes - massive rearrangements such that little remains of the original system's dynamics or functions [39]. For example, rising temperatures in the 
Northern Hemisphere shift tree species distributions with profound effects on the composition and internal processes of boreal forests $[9,40]$. New communities that reflect species' dispersal and survival abilities under warmer conditions will emerge, resulting in different resource use, habitat for wildlife species, disturbances, and potential for human use [41].

Any prediction of the response of an ecosystem experiencing unprecedented events or conditions, such as a changed climate, is an extrapolation. Typically, multiple factors act on forest ecosystems simultaneously, adding another layer of uncertainty to such extrapolations. Predicting the response of forests to management or restoration treatments under altered environmental conditions is an example of multilayered uncertainty [42].

\section{Non-linearity and Uncertainty: Making It Work for You}

Acknowledging non-linearity and uncertainty in forest dynamics and management, in conjunction with increasingly rapid changes in ecological, social, and economic conditions in the world today, highlights that practices and management regimes that favor simplistic and stable forest composition and structure are problematic. If nothing else, an appreciation of how non-linearity and uncertainty have resulted in many surprises in the past should instill a sense of humility among forest managers and help them acknowledge that we cannot control the precise future of any tract of forest. Thus, foresters are challenged to find ways to manage forests in the face of non-linearity and uncertainty that encourages a suite of stand and landscape conditions that can provide a wide range of desirable outcomes under a broad set of "surprises" [5••, 43].

Such changes in attitude are already occurring for landowners, such as the US National Forest system. New management goals include managing for increased resilience and adaptive potential, and these goals are replacing the previous focus on timber productivity [43-45] or stability [46]. Such shifts have the highest likelihood of success if they result in flexible and adaptive management approaches that can accommodate unpredictable ecosystem behavior [47]. Currently, consequences of uncertainties about future events or the non-linear behavior of ecosystems are addressed as they arise. Forest management responses to such situations that are based on the command and control approach include pesticide applications (e.g., for insect outbreaks), weed control and/or planting operations (e.g., lack of propagule sources for natural regeneration), and fertilization (e.g., nutrient deficiencies).

An alternative to such high input and impact treatments is to acknowledge and incorporate aspects of complex adaptive systems into forest management plans. Addressing the nonlinearity in forest dynamics and uncertainty in forest management described above provides unique opportunities for future research and refinement of various forest management approaches. Understandably, the inherent unpredictability of complex systems and great uncertainty in future conditions are hard to accept for a profession, which has taken pride in making forests homogenous and predictable. Foresters have to take a new critical look at the value of precision in yield tables and growth models, standard prescription guidelines, and silvicultural rules [10].

To suggest how complexity, particularly non-linearity and uncertainty, can be incorporated into forest management, we propose three broad solutions: (1) relaxing and expanding the sustained-yield and single-product paradigm, (2) moving the target for assessing success in silviculture from predetermined strict outcomes for each and every stand to an envelope of possible outcomes that are acceptable for one or multiple stands, and (3) using new approaches and modeling tools to assess as large a range of possible outcomes as possible.

\section{Relaxing and Expanding the Sustained-Yield and Single-Good Paradigm}

We must broaden the scope of forestry practices beyond a narrow focus on a few currently valuable timber products. Given the long-term development of forests, we need to acknowledge our increasing uncertainty about (1) the future timber values and quality requirements for any tree species, (2) which tree species is most likely to grow well or even to survive in response to rapidly changing biophysical conditions, and (3) the future importance and values of other ecosystem goods and services, such as carbon, water, and recreation. As an alternative, we propose (see also e.g., the USDA as described in Peterson et al. [43]) that future management plans provide flexibility in outcomes where, depending on stand composition and structure, management would be aimed at increasing the resistance, resilience, or adaptive capacity of the stand to known and unknown future conditions. This can deliver a basis to maintain a broad set of future possibilities.

Also, instead of projecting the sustained-yield of only one service (wood) and only the most desirable tree species, more and more studies are actually modeling how different forest management practices can accommodate or optimize many different services [48]. Tree carbon storage, for example, is now increasingly recognized as an important forest function and it has become a central point in climate change discussions $[49,50]$. Strong trade-offs among supply, regulation, and cultural ecosystem services have been identified and described [48, 51, 52].

All of these changes mean that we need to relax or modify the very principle at the core of forestry; sustained-yield. By accepting that the forest composition may change (or indeed should change) to adapt to global change, it also means that the way we calculate sustained-yield needs to be adjusted so 
that current harvest of some key species would not be dependent on the sustained production of that species over 100 to 150 years as is currently done in most jurisdiction in Canada. Such an approach actually does not make sense anymore in light of the current rapidly changing climate. The current chief forester of Quebec is considering reducing significantly the number of years over which the sustained-yield (or annual allowable cut) needs to be calculated to allow forest managers to start modifying the future composition of the forest away from the current composition without imposing harvesting penalties on forest companies (Gérard Szaraz, Pers. Comm.).

One recommendation is to manage for a diversity of tree species that have a high functional diversity, i.e., contribute to a wide variety of ecosystem processes and functions [53], thus supporting multiple ecosystem services. Focusing on building adaptive capacity shifts the decision matrix and requires foresters to emphasize the diversity of functional "response traits," i.e., traits that determine a species response to disturbances. This type of management is more likely to ensure that the future forests will continue to provide us with many of the ecosystem services that are demanded by the public today and with potentially novel services that are currently not considered.

Practically, functionally diverse, mixed-species stands support species with different biotic and abiotic sensitivities and recovery mechanisms following disturbances. Different vulnerabilities and multiple response mechanisms are crucial to ensure the ability of ecosystems to self-organize, a key component for adaptive capacity. There is growing evidence that diversity can promote the sustainability of social-ecological systems in the long run through increasing their resilience [54]. Higher tree species diversity has also been shown to often produce higher levels of many ecosystem services $[55,56]$.

Moreover, it seems likely that economic prospects could be enhanced by adopting more flexible standards of acceptability. Most forest managers could probably recall costly interventions that did not meet expectations or were counterproductive when market value for some tree species changed. Some examples include growth and yield of many intensive plantations being much lower than expected due to unexpected biotic disturbance [57], tropical silvicultural interventions that did not succeed in maintaining yield [58], and low wood prices for one tree species, such as red alder in the Pacific Northwest of the USA that promoted its replacement by another higher-valued tree species, such as Douglas-fir. After millions of dollars were spent removing red alder, prices increased to the point that several companies actually started to plant red alder. More realistic cost/ benefit analyses that incorporate diverse ecosystem services and some levels of uncertainties are likely to generate very different management strategies [59].

\section{Moving the Target for Forest Management From Stand to Landscape}

Based on the idea of cross-scale interactions, complexity science suggests that acknowledging multiple spatial and time scales in making predictions may be helpful in making better management decisions [43]. For example, due to a different set of biophysical constraining forces in stands and landscapes, managers are more likely to successfully predict trends in forest composition, structure, and productivity at larger spatial scales, while at the same time, acknowledging that predictions for specific stands are not as reliable (e.g., Norden et al. [60]). Accepting less "control" and more variability at neighborhood and stand scales provides managers with more flexibility to accommodate the surprises coming from non-linearity and self-organization in forest dynamics and thus greater ecosystem adaptability at landscape or regional scales (for an example, see Mah et al. [61]).

Forest managers overseeing large private or public forest estates should attempt to manage these forests to a prescribed envelope of possible future stand conditions, rather than forcing each and every stand to move to a specific predetermined condition, as indicated in yield tables or growth models (see Fig. 4, shaded areas A and B). This envelope of possible future conditions can be described as a distribution of possible stand

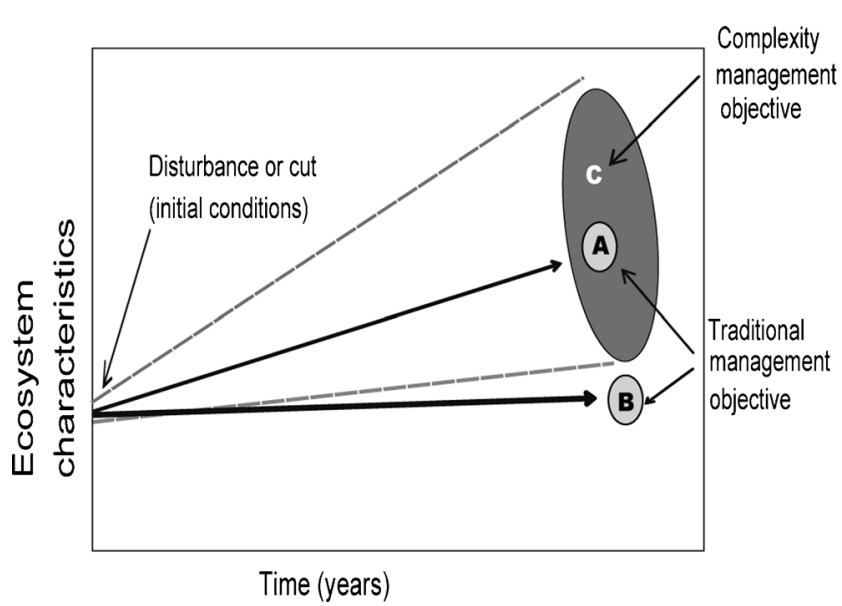

Fig. 4 Trajectories of possible ecosystem characteristics between traditional and complexity management. Point $A$ represents a possible stand being managed by selective cutting, following a severe natural disturbance or a clear-cut, in which structural heterogeneity increases with time, but in a predicted manner due to management. In such case, the diameter distribution will tend to be very similar from one part of the stand to another and among stands. Point $B$ represents the same forest as for point $A$, but managed as an even-aged monospecific stand throughout the rotation. In this case, the management is so intense that the diameter distribution is maintained outside the natural variability normally found in similar unmanaged forests. Point $C$ represents again the same forest but either left alone or managed for complexity where the silvicultural treatment is allowed to vary both within each stand and among stands. In that instance, the forest manager is not predicting or managing for one specific outcome, but a possible variety of outcomes that allow the stand to be "creative" in finding its own dynamic and complexity 
conditions that reflects the attractors of natural forest succession under some specific biophysical conditions (Fig. 4, shaded area C). Giving up specificity in prediction for any particular stand may seem a step back from our efforts to manage forests on a scientific basis since much efforts have been spent developing tools to provide higher predictability. But, "forcing" a stand to develop into a specific predetermined condition may forestall its adaptive capacity because future conditions cannot be predicted with precision due to the non-linearity of many ecological and social processes. For smaller estates, a possible approach could be to consciously maintain or promote a higher diversity of tree species and manage for a diversity of possible development trajectories. In all cases, forest management practices instead should ensure that forests do not develop outside the envelope of stand conditions as defined by the likely future biophysical environment, and of course, by the current and known possible future desired goods and services. Such envelopes may aid foresters in allowing ecosystems to respond to natural or human disturbances without seeing the necessity for intervention, as long as the end trajectories of various stand or landscape conditions are not compromised. Descriptors of the distribution of possible outcomes, which could include mean conditions and associated variability around the mean, can be used to calculate management outputs. Thus, the idea of predictability is not abandoned, but used at a level that is more appropriate for the behavior of complex socio-ecological systems subjected to rapidly changing biophysical and social conditions [62]. In this case, predictability switches from strict outcomes for each and every stand to an envelope of possible outcomes that are acceptable for one or multiple stands in the landscape (see also the approach used by Hummel and Barbour [63]).

This approach obviously requires further research, e.g., how to determine such envelopes and populate them for a variety of landscapes and ownership objectives. For broader implementation, forest managers must be able to develop these distributions on their own. However, by "loosening the grip" on predictability, such efforts may be more than offset by managers actually gaining a lot of flexibility and saving time and resources otherwise allocated to counter stochastic and natural processes driving the dynamics of each and every stand. Success of management operations should be measured at multiple spatio-temporal scales rather than only at stand and rotation age scales [62] (Fig. 4).

Accepting more variability in stand structure and tree species composition should require less management inputs while increasing the overall resilience and adaptive capacity of these stands to unknown future conditions. Even the often discussed objective of promoting or re-establishing the historic range of variability in forest conditions and processes (often referred to as Ecosystem Management; Swetnam et al. [64]) dear to many ecologists in North America may need to be relaxed [65]. While such information can provide interesting insights, it may not allow for the promotion of novel response-type diversities that are necessary to enable ecosystems to adapt to unprecedented future conditions [41].

Rather than focusing on specific predictions, foresters need to shift scales and focus on probabilities. This approach can be compared to insurance companies. They acknowledge uncertainty and do not predict whether or not a specific house will burn. Instead, they have a very successful business model by relying on information about fire probabilities (equivalent to the landscape envelope described above) to calculate insurance premiums for specific houses. Accepting a wider range of possible outcomes for individual stands (see Fig. 4) will require acceptance of variability within and among stands. This may mean, for example, that seedling mortality in selected parts of a stand will not automatically result in replanting efforts, especially when regeneration of neighboring stands has been successful. Accepting stochastic elements as an inherent part of ecosystems also requires foresters to critically review their standards and expectations [66]. Fully stocked, undisturbed forests are viewed as the norm to which all stands have to achieve, deviations from fully stocked stands are not automatically interpreted as management catastrophes and should not reflect negatively on job evaluations or reputations of forest managers (unless obvious mistakes have been made). This also includes avoiding that the standard response for any disturbance, such as windstorms, snow breakage, or insect problems, is to salvage and bring stands back to fully stocked, (apparently) undisturbed conditions as quick as possible. Thus, incorporating risk and uncertainty does not necessarily have to result in an adjustment of trued and tried management approaches (for example, see González et al. [67]). Instead, it should be interpreted as an opportunity to avoid having to impose a narrow range of stand structures and composition on every portion of every stand [63]. It provides flexibility for managers to use a wider variety of treatments and to carefully weigh responses to unplanned events and disturbances, including simply accepting them as an inherent and therefore valuable part of the envelope of possible and desirable conditions.

\section{Using New Approaches and Modeling Tools to Evaluate Forest Management Options}

As discussed previously, the prediction of the future states of ecosystems, stands, and landscapes cannot be made with precision. Non-linear dynamics, cross-scale interactions, emergence, and constantly changing external drivers or boundary conditions (e.g., environmental variability, climate change, global economy) all contribute to future uncertainty. With this in mind, the tools that we use or develop should incorporate and accept this inherent inability to forecast precisely the future. These tools should also acknowledge that changes or adaptation to known and unknown future conditions are not 
only something that we must accept, but rather something that has to be promoted and planned from the outset in management plans. Under this new paradigm, management interventions would not be aimed at reaching a precise objective or goal in the future. Instead, interventions would aim at ensuring that the forest contains all the elements necessary to preserve its capacity to change and adapt to future conditions so as to continue to produce desirable goods and services. A good analogy would be the education of our children today. Schooling and parenting should not be aimed at producing a specific adult that will do a certain job that we predict will be necessary in 30 years, but rather a very adaptable and resilient individual that will be able to navigate through the complex and increasingly changing world of the future.

Accepting uncertainty as a normal part of your planning objective can actually be liberating since it can translate into more flexible management options. Moving away from high predictability is not only difficult to accept for managers but also for researchers. As discussed by Carpenter [13], many researchers justify their research by promising to bring more predictability into one's problem or system. Although achieving high predictability is likely possible for some systems over the short-term, it is unlikely for highly complex systems such as forests particularly over the long-term normally used by forest managers.

Given the inherent uncertainty of future forest conditions, the future of an individual stand or a regional landscape should be discussed in terms of scenarios and "envelopes" or ranges of possible future states rather than precise predictions. One envelope should include all possible future states of the stand for a single scenario, given the current knowledge of the system's state and functioning.

Incorporating uncertainty into management is being proposed as a way to help adapt forest and forest management to climate change [68-70], and Yousefpour et al. [71] provided a nice review of the many approaches, models, and tools that have been used or proposed so far. Such approaches as scenario analysis, real options and simulation modeling can all be used to evaluate risk and uncertainty in forest management. In scenario analysis, the future of a stand can be conceived in terms of an envelope composed of likely future states, given a particular management scenario and external drivers. A series of scenarios may be explored through modeling to ascertain which policies and management interventions will keep the stand within an acceptable range of possible outcomes. The best use of simulation models is to develop and explore future scenarios and to serve as decision support tools by allowing greater insight into the possible responses of the system to proposed policies as was done by [72].

Models that represent the local behaviors and interactions of individuals with representations of environmental processes are increasingly being used for scenario building. A good example of such an approach was done by Temperli et al. [72]. Using a process-based forest model (LandClim), they simulated both forest dynamics and various forest goods and services under a range of climatic and management scenarios for a diverse landscape in central Europe. Interestingly, their main conclusions were that (1) adapting this forest to future climate could be done by balancing both conservation and production goals and (2) different tree species mixtures having different drought tolerance should be maintained to facilitate adaptation over time.

As demonstrated by Temperli et al. [72] and many other similar recent papers (e.g., [73-75]) rather than focusing on a single, optimal vision of the future, forest managers should use adaptive management, scenario building, and dynamic models to explore an envelope of probable futures that becomes wider the further forward one projects [76-78]. Planners could then quantify the likelihood of each scenario using sensitivity analyses or expert knowledge analysis (e.g., [79]) to address the ranges of uncertainties in ecological, social, and economic dimensions.

We know that social, economic, climatic, and ecological conditions 100 years from now will be unlike current or past conditions. Changing conditions must be anticipated rather than just recognized as they occur, since a reactive approach when dealing with long-lived organisms such as trees may be ineffective or detrimental. This challenge is probably the most pressing issue facing forest managers and policy makers today. Some cases will likely require conscious management for a different future forest composition to increase resilience to known, unknown, and unknowable future conditions [41, 80].

There is an increasing variety of new models and approaches that can be used to simulate stands and landscapes in more "complex" ways. Many are even able to incorporate changing conditions to predict the likely future conditions of the forest. Traditional growth and yield models that are deterministic and non-spatial (e.g., [81]) are not very useful in this context. More recent models that use trees as individual modeling agents and are spatially explicit (e.g., PTAEDA2: [82]) represent a significant advancement. Models that simulate forests by incorporating regeneration and growth routines at various spatial scales (e.g., SORTIE-ND: [83, 84]) and that include important natural disturbance events such as fire and insect epidemics (e.g., LANDIS-II: [85]) are even better suited to help managers understand the envelope of desirable future stand structures.

Efforts of various research groups around the globe to develop stochastic and spatially explicit models of forest developments are encouraging. Recent developments in Bayesian Networks (for examples of their use in ocean and fishery research, see Hoef [86]; Lee and Rieman [87]; Borsuk et al. [88]) and linkages to climate change models will further improve forest simulation models. However, rather than approaching these models with a mindset of improving predictability of forest development under specific conditions, development and use of the models should draw upon a solid 
understanding of the characteristics of complex adaptive systems, especially accepting uncertainty and unpredictability as intrinsic and desirable characteristics of any individual forest stand.

Since ecosystems are fundamentally a network of interacting elements, new models and modeling approaches need to be able to represent the important elements of the system both spatially and temporally [89]. Complexity models require an organizational hierarchy to represent their system of interest [90-92]. To simulate the intricate functions of a forest, a model will need to represent, in a spatially explicit manner, the most important objects and functions that affect its shortand long-term dynamics at more than one spatial scale. Many hierarchical representations are possible, but in most cases, they will encompass some or all of the following levels (individuals $<$ populations $<$ communities $<$ ecosystems $<$ biomes). Complexity theory also implies that it is not possible to simulate complex behaviors in stands by using whole stands as modeling agents because no interacting elements are present that can generate emergent properties at the stand scale. In fact, ecosystem structures, functions, and processes are now interpreted as emerging from inter-hierarchical interactions. For example, the slow (e.g., tree succession) and fast variables (e.g., insect dynamics) of Gundersen and Holling [93] represent interactions occurring across two time scales. Complex behavior is always represented using a "bottom-up" approach to modeling. In such an approach, each hierarchical element is modeled as a discrete agent or object state, where each entity has functions that are characterized by relationships described by rules (or equations) and constant values or variables.

These are just some broad guidelines to be used to simulate forests as complex adaptive systems. For any model, the hierarchical levels being represented, the spatial and temporal scales used, and the functions and variables represented depend on the questions being asked, the available data, and the skills of and the approach used by the modelers. What is important to remember here are the basic elements that are required in such models to be used to simulate complex behaviors: (1) representation of many hierarchical levels, (2) representation of both spatial and temporal scales, (3) some stochasticity, (4) some non-linearity, and (5) some representation of discrete entities or elements.

\section{Concluding Remarks}

We conclude by summarizing five key elements that need to be incorporated into forest management to accommodate nonlinearity and uncertainty:

- Consider as wide a variety of ecosystem components (i.e., more than trees), functions, and ecosystem services as possible. This would be likely to make it desirable to maintain a diverse set of forest conditions (see third element below).

○ Abandon the "command and control" approach for each and every stand. Instead, allow stands to develop within an acceptable envelope of possible conditions (Fig. 4), measure success at the landscape scale rather than the stand scale, and allow for multiple development trajectories at lower scales. Management of forests should accept variability in space and time as an inherent desirable attribute that allows forests to be more resilient and adaptive to new internal and external biotic and abiotic conditions.

o Actively and purposely maintain and develop withinand among-stand heterogeneity in ecosystem structure, composition, and function to recreate the necessary variability in forest conditions and processes that favors resilience and adaptive capacity. This could mean, in some situations, bringing in novel species so as to increase the adaptive capacity of forest landscape (sensu Lindenmayer et al. [94]).

o Evaluate current management practices according to the list of the eight characteristics used to describe complex adaptive systems as done in Fig. 1. This will provide insights about what needs to be changed in the current approach.

○ Use approaches and models to evaluate as wide a range of possible biophysical and socioeconomic factors over time as possible in order to capture the inherent uncertainty of your system. Such approaches and models are reported more and more in the scientific literature, and managers should familiarize themselves with those new tools.

Managing forests incorporating non-linearity and uncertainty has several implications for forest managers. First, forests that have developed heterogeneous structure, function, and composition rather than being managed to a specific, narrow set of stand structures would tend to be better able to adapt to changing abiotic and biotic conditions. This adaptability is especially critical because of the rapid pace of climate change and species invasions. Second, accepting unpredictability as an inherent feature of forests decreases the emphasis on managing all forests according to a single set of "best" management practices. It therefore allows for more flexibility from managers who can accept a range of developments as long as the whole forest achieves the desirable economic, social, and ecological objectives. In many cases, this will result in lower costs, reduced ecological impacts, greater adaptability, and higher social acceptance. Third, forest management should be based on the knowledge that non-linear, interrelated causes and feedback loops that span hierarchical levels of organization and encompass many multiple spatial and temporal scales are all inherent features of ecosystems. It is this multiplicity of 
factors occurring at various scales that are necessary to allow forests to recover quickly after a wide range of disturbances, adapt to climate change, and resist species invasions.

The proposed changes pose deep philosophical and practical challenges to current forest management thinking. It will not be easy for many managers to abandon the agricultural view that forests are controllable systems and that efficient management requires homogenization of stand structures. Awareness of, and openness to, the work of complexity scientists will hopefully facilitate this shift in thinking. As discussed by Messier et al. [5••] in their last chapter, complexity science provides a conceptual framework for many of the modifications and adaptations to forest management (e.g., variable retention, ecosystem management, or close to nature forestry) that have already been implemented in the recent decades. It is a valuable template that can guide the further improvement of these recent forest management approaches and practices in the future.

\section{Compliance with Ethical Standards}

Conflict of Interest The authors declare that they have no conflict of interest.

Human and Animal Rights and Informed Consent This article does not contain any studies with human or animal subjects performed by the author.

\section{References}

Papers of particular interest, published recently, have been highlighted as:

- Of importance

•- Of major importance

1. Holling CS, Meffe GK. Command and control and the pathology of natural resource management. Conserv Biol. 1996;10:328-37.

2.• Messier C, Puettmann K, Chazdon R, Andersson K, Angers V, Brotons L, et al. From management to stewardship: viewing forests as complex adaptive systems in an uncertain world. Conserv Lett. 2015;8:368-77. This paper makes the case for a new forest management paradigm that uses the science of complexity and the properties of complex adaptive systems. It describes what are the shortcomings of the current forest management paradigm that does not consider uncertainty, non-linearity and the adaptive capacity of forest ecosystems.

3. Filotas E, Parrott L, Burton PJ, Chazdon RL, Coates KD, Coll L, et al. Viewing forests through the lens of complex systems science. Ecosphere. 2014;5:1-23. This paper describes how forest ecosystems can be better understand by viewing them as complex adaptive systems. It reviews the properties of complex adaptive systems using four different forest biomes (temperate, boreal, tropical and mediterraneen).

4. Levin S, Xepapadeas T, Crépin A-S, Norberg J, De Zeeuw A, Folke $\mathrm{C}$, et al. Social-ecological systems as complex adaptive systems: modeling and policy implications. Environ Dev Econ. 2013;18: 111-32.

5.• Messier C, Puettmann KJ, Coates KD. Managing forests as complex adaptive systems: building resilience to the challenge of global change. New-York, NY: Routledge; 2013. This book reviews what we know about complex adaptive systems and how this knowledge can be applied to help better manage the world forests. Different world renown forest ecologists and silviculturists review the forests they know well and explain how complexity science can be used to better understand and manage them.

6. Mitchell, M. Complexity: A guided tour. Oxford and New-York: Oxford University Press; 2009

7. Solé RV, Bascompte, J. Self-organization in complex ecosystems. Princeton, New Jersey: Princeton University Press; 2006

8. Paquette A, Messier C. Managing forests as complex adaptive systems: building resilience to the challenge of global change. In: Messier C, Puettmann KJ, Coates D, editors. Managing tree plantations as complex adaptive systems. London: Routeledge; 2013.

9. Woods A, Coates KD, Hamann A. Is an unprecedented Dothistroma needle blight epidemic related to climate change? Bioscience. 2005;55:761-9.

10. Puettmann K J, Coates KD, Messier C. A critique of silviculture: managing for complexity. Washington: Island Press; 2009

11. Levin SA. Ecosystems and the biosphere as complex adaptive systems. Ecosystems. 1998;1:431-6.

12. Ciancio O, Nocentini S. Biodiversity conservation and systemic silviculture: concepts and applications. Plant Biosystems. 2011;145:411-8.

13. Carpenter SR. Ecological futures: building an ecology of the long now 1. Ecology. 2002;83:2069-83.

14. Scheffer M, Carpenter S, Foley JA, Folke C, Walker B. Catastrophic shifts in ecosystems. Nature. 2001;413:591-6.

15. Soto DP, Donoso PJ, Salas C, Puettmann KJ. Light availability and soil compaction influence the growth of underplanted Nothofagus following partial shelterwood harvest and soil scarification. Can J For Res. 2015;45:998-1005.

16. Blasius B, Huppert A, Stone L. Complex dynamics and phase synchronization in spatially extended ecological systems. Nature. 1999;399:354-9.

17. Costantino RF, Desharnais RA, Cushing JM, Dennis B. Chaotic dynamics in an insect population. Science. 1997;275:389-91.

18. Hanski I, Woiwod I, Perry J. Density dependence, population persistence, and largely futile arguments. Oecologia. 1993;95:595-8.

19. Stone, L. and Ezrati, S. Chaos, cycles and spatiotemporal dynamics in plant ecology. Journal of Ecology. 1996;84:279-91.

20. Anderson-Teixeira KJ, Miller AD, Mohan JE, Hudiburg TW, Duval BD, DeLucia EH. Altered dynamics of forest recovery under a changing climate. Glob Chang Biol. 2013;19:2001-21.

21. Staver AC, Archibald S, Levin SA. The global extent and determinants of savanna and forest as alternative biome states. Science. 2011;334:230-2.

22. Kéfi S, Rietkerk M, Alados CL, Pueyo Y, Papanastasis VP, ElAich A, et al. Spatial vegetation patterns and imminent desertification in Mediterranean arid ecosystems. Nature. 2007;449:213-7.

23. Fahrig L. Effects of habitat fragmentation on biodiversity. Annu Rev Ecol Evol Syst. 2003;34:487-515.

24. Rietkerk M, Dekker SC, de Ruiter PC, van de Koppel J. Selforganized patchiness and catastrophic shifts in ecosystems. Science. 2004;305:1926-9.

25. Peters DP, Pielke RA, Bestelmeyer BT, Allen CD, Munson-McGee $\mathrm{S}$, Havstad KM. Cross-scale interactions, nonlinearities, and forecasting catastrophic events. Proc Natl Acad Sci U S A. 2004;101: $15130-5$.

26. Turner MG, Romme WH, Tinker DB. Surprises and lessons from the 1988 Yellowstone fires. Front Ecol Environ. 2003;1:351-8. 
27. Raffa KF, Aukema BH, Bentz BJ, Carroll AL, Hicke JA, Turner $\mathrm{MG}$, et al. Cross-scale drivers of natural disturbances prone to anthropogenic amplification: the dynamics of bark beetle eruptions. Bioscience. 2008;58:501-17.

28. Strogatz, S. H. In: Nonlinear dynamics and chaos: with applications to physics, biology, chemistry, and engineering. Boulder, Colorado: Westview press; 2014

29. De Grandpré, L., Gauthier, S., Allain, C., Cyr, D., Périgon, S., Pham, A. et al. Towards an ecosystem approach to managing the boreal forest in the North Shore region: disturbance regime and natural forest dynamics. Ecosystem management in the boreal forest. Edited by S. Gauthier, M.-A. Vaillancourt, A. Leduc, L. De Grandpré, D. Kneeshaw, H. Morin, P. Drapeau, and Y. Bergeron. Presses de l'Université du Québec, Montreal, Quebec, Canada. 2009; 229-255.

30. Johnstone JF, Chapin FS, Hollingsworth TN, Mack MC, Romanovsky V, Turetsky M. Fire, climate change, and forest resilience in interior Alaska. Can J For Res. 2010;40:1302-12.

31. Reyer CP, Brouwers N, Rammig A, Brook BW, Epila J, Grant RF, et al. Forest resilience and tipping points at different spatio-temporal scales: approaches and challenges. J Ecol. 2015;103:5-15.

32. Walker B, Salt D. Resilience thinking: sustaining ecosystems and people in a changing world. Washington: Island Press; 2012

33. Scheffer M, Carpenter SR, Lenton TM, Bascompte J, Brock W, Dakos V, et al. Anticipating critical transitions. Science. 2012;338:344-8.

34. Kot JL, May R, Schwinning S, Sugihara G, Tidd C, Turchin P, et al. Population oscillations of boreal rodents: regulation by mustelid predators leads to chaos. Nature. 1993;364:232-5.

35. Putz, F. Complexity confronting tropical silviculturists In: C. Messier, Puettmann K D. Coates. Managing forests as complex adaptive systems. Routeledge, New-York,NY; 2013. 165-186 p.

36. Nocentini, S. and Coll, L. Mediterranean forests: human use and complex adaptive systems. In: C. Messier, Puettmann K D. Coates. Managing Forests as Complex Adaptive Systems. Routeledge, New-York,NY; 2013. 214-243 p.

37. Taleb NN. In: The black swan: the impact of the highly improbable fragility. New York: Random House; 2010

38. Elmqvist T, Folke C, Nyström M, Peterson G, Bengtsson J, Walker $\mathrm{B}$, et al. Response diversity, ecosystem change, and resilience. Front Ecol Environ. 2003;1:488-94.

39. Mascaro J, Hughes RF, Schnitzer SA. Novel forests maintain ecosystem processes after the decline of native tree species. Ecol Monogr. 2012;82:221-8.

40. Gustafson EJ, Shvidenko AZ, Sturtevant BR, Scheller RM. Predicting global change effects on forest biomass and composition in south-central Siberia. Ecol Appl. 2010;20:700-15.

41. Hobbs RJ, Arico S, Aronson J, Baron JS, Bridgewater P, Cramer VA, et al. Novel ecosystems: theoretical and management aspects of the new ecological world order. Glob Ecol Biogeogr. 2006;15:1-7.

42. Puettmann KJ. Silvicultural challenges and options in the context of global change: "simple" fixes and opportunities for new management approaches. J For. 2011;109:321-31.

43. Puettmann KJ. Restoring the adaptive capacity of forest ecosystems. J Sustain For. 2014;33:S15-27.

44. Millar CI, Stephenson NL, Stephens SL. Climate change and forests of the future: managing in the face of uncertainty. Ecol Appl. 2007; 17:2145-51.

45. Peterson, D. L., Millar, C. I., Joyce, L. A., Furniss, M. J., Halofsky, J. E., Neilson, R. P. et al. Responding to climate change in national forests: a guidebook for developing adaptation options. Gen. Tech. Rep. PNW-GTR-855. Portland, OR: U.S. Department of Agriculture, Forest Service, Pacific Northwest Research Station. 2011;109.

46. Cornett $\mathrm{M}$, White $\mathrm{M}$. Forest restoration in a changing world: complexity and adaptation examples from the Great Lakes region of North America. In: Messier C, Puettmann KJ, David Coates K, editors. Managing forests as complex adaptive systems: building resilience to the challenge of global change. London: Routledge; 2013.

47. Walters C. Adaptive management of renewable resources. New York, NY: MacMillan Pub. Co.; 1986.

48. Bradford JB, D'Amato AW. Recognizing trade-offs in multiobjective land management. Frontiers in Ecology and the Environment. 2011;10:210-6.

49. Canadell JG, Raupach MR. Managing forests for climate change mitigation. Science. 2008;320:1456-7.

50. Moore PT, DeRose RJ, Long JN, van Miegroet H. Using silviculture to influence carbon sequestration in southern Appalachian spruce-fir forests. Forests. 2012;3:300-16.

51. Bennett EM, Peterson GD, Gordon LJ. Understanding relationships among multiple ecosystem services. Ecol Lett. 2009;12:1394 404.

52. Raudsepp-Hearne C, Peterson GD, Bennett EM. Ecosystem service bundles for analyzing tradeoffs in diverse landscapes. Proc Natl Acad Sci U S A. 2010;107:5242-7.

53. Díaz S, Cabido M. Vive la différence: plant functional diversity matters to ecosystem processes. Trends Ecol Evol. 2001;16:646-55.

54. Chapin III FS, Kofinas GP, Folke C, Chapin MC. Principles of ecosystem stewardship: resilience-based natural resource management in a changing world. New-York, NY: Springer Verlag; 2009.

55. Gamfeldt L, Snall T, Bagchi R, Jonsson M, Gustafsson L, Kjellander P, et al. Higher levels of multiple ecosystem services are found in forests with more tree species. Nat Commun. 2013;4:1340.

56. Paquette A, Messier C. The effect of biodiversity on tree productivity: from temperate to boreal forests. Glob Ecol Biogeogr. 2011;20:170-80.

57. Woods A, Coates KD. Are biotic disturbance agents challenging basic tenets of growth and yield and sustainable forest management? Forestry. 2013;0:1-12.

58. Dawkins HC, Philip MS. Tropical moist forest silviculture and management: a history of success and failure. 1998. CAB international.

59. Knoke T, Moog M, Plusczyk N. On the effect of volatile stumpage prices on the economic attractiveness of a silvicultural transformation strategy. Forest Policy Econ. 2001;2:229-40.

60. Norden N, Angarita HA, Bongers F, Martínez-Ramos M, Granzowde la Cerda I, Van Breugel M, et al. Successional dynamics in Neotropical forests are as uncertain as they are predictable. Proc Natl Acad Sci. 2015;112:8013-8.

61. Mah, S., Astridge, K., DeLong, C., Wickland, C., Todd, M., McAuley, L. et al. A landscape-level species strategy for forest management in British Columbia: exploration of development and implementation issues. Prov. BC, Victoria. Rep. 067. www. for.gov.bc.ca/hfd/pubs/Docs/Tr/Tr067.htm. 2012.

62. Puettmann KJ, Tappeiner JC. Multi-scale assessments highlight silvicultural opportunities to increase species diversity and spatial variability in forests. Forestry. 2013;0:1-10. doi:10.1093/forestry/ cpt050.

63. Hummel S, Barbour R. Restoring fire-adapted ecosystems: proceedings of the 2005 national silviculture workshop. Pacific Southwest Research Station, USDA Forest Service. PSW-GTR203, Albany, CA. 2007.

64. Swetnam TW, Allen CD, Betancourt JL. Applied historical ecology: using the past to manage for the future. Ecol Appl. 1999;9: 1189-206.

65. Mori AS, Spies TA, Sudmeier-Rieux K, Andrade A. Reframing ecosystem management in the era of climate change: issues and knowledge from forests. Biol Conserv. 2013;165:115-27.

66. Rivington M, Matthews K, Bellocchi G, Buchan K, Stöckle C, Donatelli M. An integrated assessment approach to conduct 
analyses of climate change impacts on whole-farm systems. Environ Model Softw. 2007;22:202-10.

67. González-Benito J, González-Benito Ó. A review of determinant factors of environmental proactivity. Bus Strateg Environ. 2006;15: 87-102.

68. Janowiak MK, Swanston CW, Nagel LM, Brandt LA, Butler PR, Handler SD, et al. A practical approach for translating climate change adaptation principles into forest management actions. J For. 2014;112:424-33.

69. Keenan RJ. Climate change impacts and adaptation in forest management: a review. Ann For Sci. 2015;72:145-67. doi:10.1007/ s13595-014-0446-5.

70. Schoene DHF, Bernier PY. Adapting forestry and forests to climate change: a challenge to change the paradigm. Forest Policy Econ. 2011;24:12-9. doi:10.1016/j.forpol.2011.04.007.

71. Yousefpour R, Jacobsen JB, Thorsen BJ, Meilby H, Hanewinkel M, Oehler K. A review of decision-making approaches to handle uncertainty and risk in adaptive forest management under climate change. Ann For Sci. 2012;69:1-15.

72. Temperli C, Bugmann H, Elkin C. Adaptive management for competing forest goods and services under climate change. Ecol Appl. 2012;22:2065-77.

73. Burgman M, Lindenmayer D, Elith J. Managing landscapes for conservation under uncertainty. Ecology. 2005;86:2007-17.

74. Dhital, N., Raulier, F., Bernier, P. Y., Lapointe-Garant, M.-P., Berninger, F. and Bergeron, Y. Adaptation potential of ecosystembased management to climate change in the eastern Canadian boreal forest. Journal of Environmental Planning and Management. 2015;58:2228-49.

75. Littell JS, McKenzie D, Kerns BK, Cushman S, Shaw CG. Managing uncertainty in climate-driven ecological models to inform adaptation to climate change. Ecosphere. 2011;2:art102.

76. Lempert RJ. A new decision sciences for complex systems. Proc Natl Acad Sci. 2002;99:7309-13.

77. Parrott L, Meyer WS. Future landscapes: managing within complexity. Front Ecol Environ. 2012;10:382-9.

78. Peterson GD, Cumming GS, Carpenter SR. Scenario planning: a tool for conservation in an uncertain world. Conserv Biol. 2003;17: 358-66.

79. Doyon, F., Sturtevant, B. R., Papaik, M. J., Fall, A., Miranda, B., Kneeshaw, D. D. et al. 2012. Assessing knowledge ambiguity in the creation of a model based on expert knowledge and comparison with the results of a landscape succession model in central Labrador. In: Expert knowledge and its application in landscape ecology. Edited by Perera A., A. Drew C Johnson (eds.), Springer, pp. $189-210$

80. Levin S. Complex adaptive systems: exploring the known, the unknown and the unknowable. Bull Am Math Soc. 2003;40:3-19.
81. Daniels, R. F. and Burkhart, H. E. In: Simulation of individual tree growth and stand development in managed loblolly pine plantations. FWS-5-75, Division of Forestry and Wildlife Resources, Virginia Polytechnic Institute and State University, Blacksburg, VA. 69 p. Dawkins, H.C. and Philip, M.S. 1998. Tropical moist forest silviculture and management: a history of success and failure. CAB International, Wallingford, UK.; 1975.

82. Burkhart, H., Farrar, K., Amateis, R. and Daniels, R. Simulation of individual tree growth and stand development in loblolly pine plantations in loblolly pine plantations plantations on cutover, siteprepared areas. Publication number FWS-1-87. Virginia Tech Department of Forestry, Blacksburg. 2001;28.

83. Bose AK, Harvey BD, Coates KD, Brais S, Bergeron Y. Modelling stand development after partial harvesting in boreal mixedwoods of eastern Canada. Ecol Model. 2015;300:123-36.

84. Coates KD, Canham CD, Beaudet M, Sachs DL, Messier C. Use of a spatially explicit individual-tree model (SORTIE/BC) to explore the implications of patchiness in structurally complex forests. For Ecol Manag. 2003;186:297-310.

85. Mladenoff DJ. LANDIS and forest landscape models. Ecol Model. 2004;180:7-19.

86. Hoef JMV. Parametric empirical Bayes methods for ecological applications. Ecol Appl. 1996;6:1047-55.

87. Lee DC, Rieman BE. Population viability assessment of salmonids by using probabilistic networks. N Am J Fish Manag. 1997;17: 1144-57.

88. Borsuk ME, Stow CA, Reckhow KH. A Bayesian network of eutrophication models for synthesis, prediction, and uncertainty analysis. Ecol Model. 2004;173:219-39.

89. Cuddington K, Fortin M-J, Gerber L, Hastings A, Liebhold A, O'Connor M, et al. Process-based models are required to manage ecological systems in a changing world. Ecosphere. 2013;4:art20.

90. Green JL, Hastings A, Arzberger P, Ayala FJ, Cottingham KL, Cuddington $\mathrm{K}$, et al. Complexity in ecology and conservation: mathematical, statistical, and computational challenges. Bioscience. 2005;55:501-10.

91. Parrott L, Kok R. Incorporating complexity in ecosystem modelling. Complex Int. 2000;7:1-19.

92. Proulx R. Ecological complexity for unifying ecological theory across scales: a field ecologist's perspective. Ecol Complex. 2007;4:85-92.

93. Gunderson LH, Holling CS. Panarchy: understanding transformations in systems of humans and nature. Washington DC: Island Press; 2002.

94. Lindenmayer D, Messier C, Paquette A, Hobbs RJ. Managing tree plantations as novel socio-ecological systems: Australian and North American perspectives. Can J For Res. 2015;45:1427-33. 